\title{
Prevalence of Hepatitis C Virus Infection among Chronic Liver Disease Patients in a Tertiary Care Hospital
}

\author{
B.N. Vilas ${ }^{1}$, P.R. Lyra ${ }^{2 *}$ and D. Venkatesha ${ }^{3}$ \\ ${ }^{1}$ Sanjay Gandhi Institute of Trauma and Orthopaedics, Bangalore, Karnataka, India \\ ${ }^{2}$ Department of Microbiology, East Point College of Medical Sciences and Research Centre, \\ Bangalore, Karnataka, India \\ ${ }^{3}$ Department of Microbiology, Adichunchanagiri Institute of Medical Sciences, Bellur, \\ Karnataka, India \\ *Corresponding author
}

\begin{abstract}
A B S T R A C T
Hepatitis $\mathrm{C}$ virus $(\mathrm{HCV})$ infection is a leading cause of chronic hepatitis and primary hepatocellular carcinoma in most parts of the world. The prevalence of HCV infection worldwide has been estimated to be about $3 \%$. Hence the present study was carried out to

Keywords

HCV, Chronic liver disease

Article Info

Accepted:

24 January 2018

Available Online:

10 February 2018 detect the prevalence of hepatitis $\mathrm{C}$ in patients of chronic liver disease. Eighty patients with clinically suspected Chronic Liver Disease attending the outpatient department or admitted in the K R Hospital attached to Mysore Medical College and Research Institute, Mysore from January 2012 to December 2012, were screened for anti-HCV. The study also included 15 asymptomatic healthy individuals who constituted the control group. $5 \mathrm{ml}$ of blood was collected from all patients with aseptic precautions, serum sample obtained were tested for serological marker anti-HCV using Erba Lisa Hepatitis C - third generation ELISA kits. Serum samples from healthy individuals included were also simultaneously screened for anti-HCV. Among the 80 chronic liver disease patients, 4(5\%) were positive for $\mathrm{HCV}$. Among the $4 \mathrm{HCV}$ positive patients, all were males. The highest percentage of HCV positivity was in the age group $31-40$ years. The main mode of transmission in $\mathrm{HCV}$ was through sexual exposure, 3 (75\%). Among the $4 \mathrm{HCV}$ positive patients, $3(75 \%)$ presented with cirrhosis of liver and $1(25 \%)$ with hepatocellular carcinoma. Among the healthy controls screened all were negative for anti HCV.
\end{abstract}

\section{Introduction}

Liver disease has a worldwide distribution (Maddrey, 2001; Davis and Roberts, 2010). Chronic liver disease (CLD) results from an inflammatory injury to the liver, which has persisted for six or more months without complete resolution. CLD comprises of a spectrum of disease such as chronic hepatitis, liver cirrhosis, and Hepatocellular carcinoma (Laraba et al., 2009).

Hepatitis $\mathrm{C}$ virus (HCV) infection is a leading cause of chronic hepatitis and primary hepatocellular carcinoma in most parts of the world. In the developing countries of Asia and Africa, though hepatitis B virus (HBV) infection is the commonest cause of chronic 
liver disease, $\mathrm{HCV}$ is fast evolving as an equally important infection among these populations (Poovorawan et al., 2002).

Hepatitis $\mathrm{C}$ virus (HCV) is a ribonucleic acid (RNA)-enveloped flavivirus, mainly transmitted by parenteral route (Puri et al., 2014). The prevalence of HCV infection worldwide has been estimated to be about $3 \%$ with 170 million people affected by HCV (Sy and Jamal, 2006). The majority of those with chronic HCV infection will develop complications i.e. $15 \%-40 \%$ may develop cirrhosis, liver failure and or hepatocellular carcinoma (Lok and McMahon, 2007). Hence the present study was carried out to detect the prevalence of hepatitis $\mathrm{C}$ in patients of chronic liver disease.

\section{Materials and Methods}

The present study was conducted in the Department of Microbiology, Mysore Medical College and Research Institute, Mysore, from January 2012 to December 2012.

Eighty (80) patients with clinically suspected Chronic Liver Disease cases irrespective of the age and sex, attending the outpatient department or admitted in the K R Hospital attached to Mysore Medical College and Research Institute, Mysore, were screened for anti-HCV. The study also included 15 asymptomatic healthy individuals who constituted the control group

$5 \mathrm{ml}$ of blood was collected from all patients with all aseptic precautions by venepuncture in sterilized labeled test tubes, centrifuged at $1000 \mathrm{rpm}$ for 5 minutes, serum separated and collected in $1.5 \mathrm{ml}$ of sterile serum vials and stored at $-20^{\circ} \mathrm{C}$ until tested. Serum sample were tested for serological marker anti-HCV using Erba Lisa Hepatitis C - third generation enzyme linked immunosorbent assay (ELISA) kits according to manufacturer's instruction.
Serum samples from healthy individuals included were also simultaneously screened for anti-HCV as per the methodology.

\section{Results and Discussion}

Among the 80 chronic liver disease patients, $4(5 \%)$ were positive for Anti HCV.

Among the $4 \mathrm{HCV}$ positive patients, all were males. The highest percentage of $\mathrm{HCV}$ positivity was $50 \%$ in the age group $31-40$ years, followed by $25 \%$ in the each age group of $41-50$ and $51-60$ years.

Among the 15 healthy controls studied, 10 $(66.7 \%)$ were males and $5(33.3 \%)$ were females. All were negative for HCV.

In the present study, the main mode of transmission in HCV was through sexual exposure $3(75 \%)$.

Among the $4 \mathrm{HCV}$ positive patients, $3(75 \%)$ presented with cirrhosis of liver and $1(25 \%)$ with hepatocellular carcinoma.

The awareness and understanding of hepatitis $\mathrm{C}(\mathrm{HCV})$ has raised dramatically over the past decades. HCV is mostly transmitted through exposure to infective blood through transfusions of HCV-contaminated blood and blood products, contaminated injections during medical procedures, and through injection drug use. Sexual transmission is also possible (Sarin et al., 2003).

Chronic infection by these viruses leads to slow progressive liver disease that result in cirrhosis, chronic liver failure and hepatocellular carcinoma (HCC).

The prevalence of $\mathrm{HCV}$ infection in the present study is $5 \%$. In India, various workers have reported prevalence of $\mathrm{HCV}$ in liver diseases patients to be between $5-10 \%$. 
Graph.1 Age and sex distribution of HCV positive patients (\% wise)

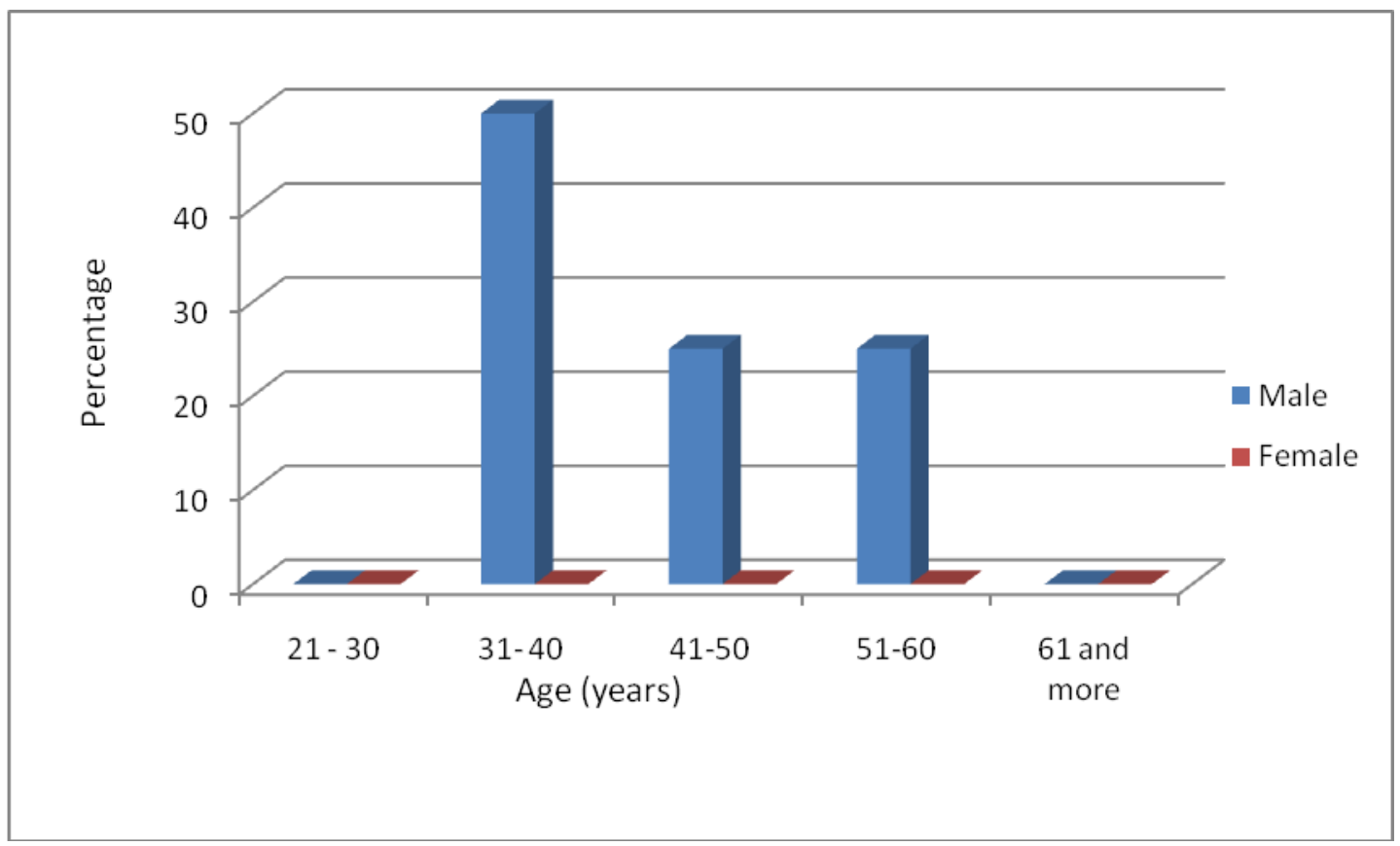

Table.1 Mode of transmission of HCV infection in chronic liver disease patients

\begin{tabular}{|c|c|}
\hline Mode of transmission & HCV (\%) \\
\hline Blood transfusion & Nil \\
\hline Sexual exposure & $3(75 \%)$ \\
\hline IV Drug abuse & Nil \\
\hline No risk & $1(25 \%)$ \\
\hline
\end{tabular}

Table.2 Clinical presentation of chronic liver disease patients with $\mathrm{HCV}$ infection

\begin{tabular}{|c|c|c|}
\hline Disease & Number screened & Number positive \\
\hline Chronic hepatitis & 14 & Nil \\
\hline Cirrhosis of liver & 65 & 3 \\
\hline Hepatocellular carcinoma & 1 & 1 \\
\hline
\end{tabular}

Guptan et al., (1996) conducted a study in Calcutta among 84 patients (62 of cirrhosis, 22 of chronic hepatitis) and reported that $7(8.33 \%)$ patients with chronic hepatitis, $5(8.06 \%)$ patients with cirrhosis and $2(9.09 \%)$ of chronic active hepatitis were $\mathrm{HCV}$ positive (Chatterjee et al., 2001).

In the present study, mean age of $\mathrm{HCV}$ positive is 45.09 years. In a study conducted by Anbazhagan et al., (2010) in Tamilnadu, $\mathrm{HCV}$ was found to be high among individuals belonging to the $41-50$ years $(28.5 \%)$ age group. HCV infections usually progress slowly to terminal liver disease. (Chen and Morgan, 2006) It is, therefore, possible to recognize the impact that the disease may have in the future based on the knowledge of its previous incidence. It is also feasible to estimate the burden of late complications 
associated directly with the presence of chronic liver disease (Armstrong et al., 2006).

All HCV positive cases are males (100\%). This concurs with a previous report from Tamil Nadu, which male subjects were at a higher risk of $\mathrm{HCV}$ infection than females (Anbazhagan et al., 2010). High prevalence of Hepatitis in males might be due to fact that males make more common visits to barber and they may be more probably to get wounded and may share equipment. Moreover, men also are more likely to have many sex partners and follow unprotected sex (Anirban Kundu et al., 2015).

The frequency of anti-HCV was significantly higher in cirrhosis as compared to chronic hepatitis and HCC patients, it is comparable with the study of Bukhtiari et al., (2000), Perz et al., (2006) and Khokhar (2002).

Thus early detection of these diseases will be helpful for proper treatment and preventing its progression to chronicity, there by morbidity and mortality can be reduced.

Seroprevalence of HCV among chronic liver disease in the present study is $5 \%$. To prevent the spread of $\mathrm{HCV}$, people must be educated about these infections and their mode of transmission. All the hospitals should implement proper infection control strategies. Furthermore all clinically diagnosed patients should be tested for HCV serostatus to prevent the mortality and morbidity.

\section{References}

Anbazhagan GK, Krishnamoorthy S, Thiyagarajan T. Seroprevalence of $\mathrm{HCV}$ and its co-infection with HBV and HIV among liver disease patients of South Tamil Nadu. World J Hepatol. 2010 Jan 27; 2(1): 42-8

Anirban Kundu, Sonia Mehta, B.K. Agrawal
Prevalence of Hepatitis B Virus and Hepatitis-C Virus among Chronic Liver Disease Patients in Northern Haryana Region of India. Journal of Medical education and research. Vol. 17 No. 4, Oct - December 2015

Armstrong GL, Wasley A, Simard EP, McQuillan GM, Kuhnert WL, Alter MJ. The prevalence of hepatitis $\mathrm{C}$ virus infection in the United States, 1999 through 2002. Ann Intern Med. 2006; 144:705-714

Bukhtiari N, Hussain T, Iqbal M. et al., Hepatitis B and C single and coinfection in Chronic Liver Disease and their effect on the Disease Pattern. Journal of Pakistan Medical Association 2000: 136-40.

Chatterjee C, Mitra K, Hazra SC, Banerjee D, Guha SK and Neogi DK. Prevalence of HCV Infection among Patients of Chronic Active Hepatitis and Cirrhosis cases in Calcutta. Indian Journal of Medical Microbiology, 2001 19(1): 4647.

Chen SL, and Morgan TR. The natural history of hepatitis $\mathrm{C}$ virus (HCV) infection. Int J Med Sci. 2006; 3:47-52

Davis GL, and Roberts WL. The healthcare burden imposed by liver disease in aging Baby Boomers. Curr Gastroenterol Rep 2010; 12(1):1-6.

Guptan, S.K., RC, Banerjee K, Khandekar P Low prevalence of hepatitis $\mathrm{c}$ viral infection in patients with non-alcoholic chronic liver disease in India JAPI, 1996, 44(4) 243-5

Khokhar N. Spectrum of Chronic Liver Disease in a Tertiary Care Hospital. J Pak Med Assoc. 2002 Feb; 52(2):56-8.

Laraba A, Wadzali G, Sunday B, et al., Hepatitis C Virus Infection In Nigerians With Chronic Liver Disease. Internet $J$ Gastroenterol 2009; 9(1):1-3

Lok ASF, and McMahon BJ. Chronic hepatitis B. Hepatology 2007; 
45(2):507-39.

Maddrey WC. Update in hepatology. Ann Intern Med 2001; 134(3):216-23.

Perz JF, Armstrong GL, Farrington LA, Hutin YJ, Bell BP. The contributions of hepatitis $B$ virus and hepatitis $C$ virus infections to cirrhosis and primary liver cancer worldwide. J Hepatol 2006 Oct; 45(4):529-38.

Poovorawan Y, Chatchatee P, Chongsrisawat V. Epidemiology and prophylaxis of viral hepatitis: a global perspective. $J$ Gastroenterol Hepatol 2002; 17 Suppl:S155-66.
Puri P, Anand AC, Saraswat VA, et al., Consensus statement of HCV task force of the Indian national association for study of the liver (INASL). Part I: status report of HCV infection in India. J Clin Exp Hepatol. 2014; 4:106-116.

Sarin S. C. Smelzer and B. Bare, Brunner and Suddarth's Textbook of Medical Surgical Nursing, Lippincott Williams \& Wilkins, Philadelphia, Pa, USA, 2003

Sy T, and Jamal MM. Epidemiology of hepatitis $\mathrm{C}$ virus (HCV) infection. Int $J$ Med Sci 2006; 3(2): 41-6.

\section{How to cite this article:}

Vilas, B.N., P.R. Lyra and Venkatesha, D. 2018. Prevalence of Hepatitis C Virus Infection among Chronic Liver Disease Patients in a Tertiary Care Hospital. Int.J.Curr.Microbiol.App.Sci. 7(02): 2489-2493. doi: https://doi.org/10.20546/ijcmas.2018.702.303 